\title{
Equilibrium and Thermodynamic Investigation of Biosorption of Nickel from Water by Activated Carbon Made from Palm Kernel Chaff
}

\section{Chidozie Nnaji}

University of Nigeria, Nsukka

\section{Edward Agim}

University of Huddersfield

\section{Cordelia Mama}

University of Nigeria, Nsukka

PraiseGod Emenike ( $\sim$ praisegod.emenike@covenantuniversity.edu.ng )

Covenant University

Nkpa Ogarekpe

Cross River University of Technology

\section{Research Article}

Keywords: adsorption, nickel, isotherm, ion exchange, thermodynamics, water, maximum adsorption capacity, equilibrium.

Posted Date: December 15th, 2020

DOI: https://doi.org/10.21203/rs.3.rs-124132/v1

License: (c) (1) This work is licensed under a Creative Commons Attribution 4.0 International License. Read Full License

Version of Record: A version of this preprint was published at Scientific Reports on April 8th, 2021. See the published version at https://doi.org/10.1038/s41598-021-86932-6. 


\section{Author's List}

1. Chidozie Charles Nnaji

Department of Civil Engineering, University of Nigeria, Nsukka

Faculty of Engineering and Built Environment, University of Johannesburg +234-8038948808

Chidozie.nnaji@unn.edu.ng

2. Edward Agim

Department of Computing and Engineering, University of Huddersfield

Queensgate Huddersfield, HD1 3DH, United Kingdom

eddyczar@yahoo.com

3. Cordelia Nnennaya Mama

Department of Civil Engineering, University of Nigeria, Nsukka +234-8063711674

Cordelia.mama@unn.edu.ng

4. Emenike, PraiseGod Chidozie *

Department of Civil Engineering,

Covenant University, Ota, Ogun State, Nigeria

Cranfield Water Science Institute,

School of Water, Energy and Environment,

Cranfield University, MK43 0AL, Bedford, United Kingdom

praisegod.emenike@covenantuniversity.edu.ng

praisegod.emenike@cranfield.ac.uk

*(Corresponding author)

$+2348036051722$

5. Ogarekpe, Mba Nkpa

nkpaogarekpe@yahoo.com

Department of Civil Engineering,

Cross River University of Technology, Calabar, Nigeria

*Correspondence should be sent to praisegod.emenike@ covenantuniversity.edu.ng 


\title{
Equilibrium and Thermodynamic Investigation of Biosorption of Nickel from Water by Activated Carbon Made from Palm Kernel Chaff
}

\begin{abstract}
Novel biosorbents were derived from a waste product of palm kernel oil extraction known a palm kernel chaff (PKC). One portion of the PKC was carbonized in a furnace and then activated chemically while the other half was activated without carbonization. Both were designated as CPKC and UPKC respectively. The two biosorbents so produced were then used to conduct batch equilibrium sorption studies at $30^{\circ} \mathrm{C}, 35^{\circ} \mathrm{C}$ and $40{ }^{\circ} \mathrm{C}$ and $\mathrm{pH} 3.0$ and 9.0. The Koble-Corrigan, Dubinin-Radushkevich and the Freundlich isotherms fitted the experimental data very well with $\mathrm{R}^{2}$ values of 0.97 to $1.0,0.95$ to 1.0 and 0.96 to 1.0 respectively. The linear type II Langmuir isotherm performed much better $\left(0.96 \leq \mathrm{R}^{2} \leq 1.0\right)$ than the nonlinear isotherm. The maximum sorption capacity was obtained as $120.6 \mathrm{mg} / \mathrm{g}$ using $\mathrm{CPKC}$ at $\mathrm{pH} 9.0$ and $35^{\circ} \mathrm{C}$. The values of Langmuir separation coefficient $\left(0.022 \leq \mathrm{R}_{\mathrm{L}} \leq 0.926\right)$ show that the sorption of nickel to PKC is favourable. The most favourable sorption condition was found for $\mathrm{CPKC}$ at $\mathrm{pH} 9$ and temperature of $40{ }^{\circ} \mathrm{C}$. The values of sorption energy $(8.21 \leq \mathrm{E} \leq 14.27)$ and the isosteric heat of sorption ($\left.133.09 \leq \Delta \mathrm{H}_{\mathrm{x}} \leq-17.92\right)$ indicate that the mode of sorption is mostly ion exchange. Thermodynamic parameters also show that the process is exothermic and entropy-driven.
\end{abstract}

Keywords: adsorption, nickel, isotherm, ion exchange, thermodynamics, water, maximum adsorption capacity, equilibrium.

\section{Introduction}

Aggressive industrialization has given rise to heightened concentration of heavy metals in both surface and ground waters. The presence of heavy metals in the human environment in concentrations above permissible limits constitutes serious environmental and public health risk, and can cause irreversible damage to plant and animal health ${ }^{1}$. Nickel is a naturally occurring heavy metal existing in various mineral forms and may be found throughout the environment including rivers, lakes, oceans, soil, air, drinking water, plants, and animals. Soil and sediment are the primary receptacles for nickel, but mobilization may occur depending on physico-chemical characteristics of the soil ${ }^{2-5}$. Nickel is used extensively in the electronic and metallurgical industries, specifically in electroplating, nickel-cadmium batteries, printed circuit boards, liquid 
crystal displays; and is emitted into the environment through anthropogenic sources such as fuel combustion, smelting, sewage and solid waste management and fertilizer application ${ }^{1,6-9}$. Effluent from such industrial processes require treatment to permissible levels before discharge. The removal of metals from effluents is a major problem due to the difficulty in treatment by conventional treatment methods. Some evidence suggests that nickel may be an essential trace element for mammals ${ }^{10}$, though its concentration in water above permissible limits is of concern to public health. As for most metals, the hazardous nature of nickel hinges on its solubility and exposure route ${ }^{11}$. The inhalation route to some nickel compounds often results in toxic effects in the respiratory region and also impact on the immune system ${ }^{3,10,12-14}$. When consumed in huge amounts (> $0.5 \mathrm{~g})$ through oral intake, some forms of nickel pose acute toxicity to humans, resulting in elevated skin irritation, cardiovascular diseases, as well as cancer ${ }^{15-18}$. Several treatment processes such as chemical precipitation, adsorption, ion exchange and membrane filtration have been deployed over the years to eliminate metal(oid)s in water and industrial wastewaters. However, most of these techniques have some disadvantages, such as complicated treatment process, high cost and high energy requirement ${ }^{19,20}$.

Over the years, biosorption has become a lucrative and promising wastewater treatment technique for extracting metal(oid)s. According to Saha and Chowdhury ${ }^{21}$, the effectiveness of the adsorption technique has been outstanding in the removal of soluble heavy metal ions, synthetic dye molecules and other toxic chemicals from aqueous solution. Owing to the fact that adsorption is a cost-effective, highly efficient, and easily implemented method, its implementation made it a welcomed alternative to conventional treatment processes ${ }^{22}$. Activated carbon, being one of the popularly used adsorbent, is mainly composed of carbonaceous materials with improved porosity to adsorb chemical ions. Its internal surface area and relatively high mechanical strength, makes it 
suitable for the removal of heavy metals from wastewaters ${ }^{20,23-25}$. As a result of the advancement in adsorption technology, the demand for activated carbon is skyrocketing, and over time, making it an expensive material. However, low-cost forest and agricultural wastes without or with little processing are considered promising biosorbents for heavy metals due to their high surface areas, microporous attributes and surface chemical nature ${ }^{26-28}$. The need to explore the possibility of waste-derived biosorbent is more pressing now than ever in the light of the environmental consequences of felling trees to make activated carbon. The conversion of organic waste materials into activated carbon will also reduce the ever-increasing burden of solid waste management. Agricultural wastes and other wastes of organic origin have been found suitable for heavy metals removal from water by adsorption. It is believed that efficient conversion and utilization of waste materials will go a long way to mitigate environmental pollution and degradation as well as reducing the cost of waste treatment. Biosorbents like coconut shell, nutshells, oil palm waste, pine needles, sawdust, waste straw, rice husk, peanut hulls, hazelnut shells, almond shells, peach stones, tea dust leaves, apple wastes, sugarcane bagasse, coffee grounds, banana and orange peels, sugar beet pulp and different other materials have all been used as biosorbents with varying degrees of success ${ }^{19,20,23,25,26,29-33}$.

This study focuses on the beneficial application of palm kernel chaff, a by-product of palm kernel oil extraction. During extraction of palm kernel oil, palm cake and palm oil chaff are generated as by products. While palm kernel cake is usually the by-product of palm kernel oil extraction from screw press, palm kernel chaff usually results from local extraction (Figure 1). The local process is two-staged. The first stage consists of heating the palm kernel to expel loosely bound oil while the second stage involves crushing the charred palm kernel in a screw press. The resulting slurry is then separated into oil and chaff. Palm kernel cake is used either as high-protein feed for dairy 
cattle or burned in boilers to generate electricity for palm oil mills and surrounding villages. Though the palm kernel cake is partly composed of the chaff, we have thought it necessary to distinguish between the two because palm kernel cake is more valuable than palm kernel chaff. Palm kernel cake is a source of fiber, protein as well as other essential elements such as magnesium, iron, calcium and zinc making it well-suited for animal feed ${ }^{34}$. Studies have been conducted on the use of palm kernel palm kernel shell, oil palm fibre and palm kernel cake as adsorbent ${ }^{35-37}$. None was found on the use of palm kernel chaff as an adsorbent. This study undertook a comprehensive investigation of the physicochemical conditions for biosorption of nickel from water by activated carbon made from palm kernel chaff (PKC), a waste biosorbent.

Figure 1: Process flow for primary components of palm fruit

\section{Methodology}

\subsection{Collection and Preparation of Adsorbents}

Palm kernel chaff (PKC) was obtained from a local palm kernel extraction point in Nsukka, Enugu State, Nigeria. The PKC was air dried for five days and then sieved using standard sieve numbers $8,10.16,20,22,25$ and 30 corresponding to $2.36 \mathrm{~mm}, 2.0 \mathrm{~mm}, 1.18 \mathrm{~mm}, 0.85 \mathrm{~mm}, 0.71 \mathrm{~mm}, 0.6$ $\mathrm{mm}$ and $0.36 \mathrm{~mm}$ respectively. Particles passing through sieve size $0.36 \mathrm{~mm}$ were collected and used for the experiment. The sample was washed severally with de-ionized water and then dried in a vacuum oven at $103{ }^{\circ} \mathrm{C}$ until completely dry. The sample was then divided into two equal parts: A and B. This was done in order to ascertain the effect of carbonization on the sorption characteristics of PKC. Sample A was further carbonized in a furnace at a controlled temperature of $250{ }^{\circ} \mathrm{C}$ for 2 hours and then washed with de-ionized water. It was then dried in a vacuum oven until completely dry. Sample B was not carbonized in a furnace. Samples A and B were separately 
activated chemically by soaking and slurry for 3 hours using $0.5 \mathrm{M}$ hydrochloric acid. The gases formed due to exothermic reaction were allowed to escape for 10 minutes and the mixture was covered with a lid for 3 hours. This was followed by repeated washing with de-ionized water for complete removal of traces of the chemical and oven drying for 3 hours at $110^{\circ} \mathrm{C}$. The samples were then milled separately in a porcelain jar to increase the specific surface area by reducing lumps. Thereafter, the samples were then cooled and placed in two separate clearly labelled airtight plastic containers to keep away moisture and dust for further use. Sample A was designated as carbonized palm kernel chaff (CPKC) while sample B was designated as uncarbonized palm kernel chaff (UPKC). Ten grams (10 g) each of Samples A and B were extracted and sent to the National Geosciences Research Laboratory Kaduna, Nigeria, for chemical composition analysis by $\mathrm{x}$-ray fluorescence $(\mathrm{XRF})$. The point of zero charge $\left(\mathrm{pH}_{\mathrm{zpc}}\right)$ of the adsorbents was determined in the Public Health Laboratory of the Department of Civil Engineering, University of Nigeria. The point of zero charge was used to investigate the variation of the surface charge of palm kernel chaff with change in the $\mathrm{pH}$ of the solution. Following the method described by Singh et al. ${ }^{38}$, a solution of $\mathrm{NaCl}(0.01 \mathrm{M})$ was prepared and $50 \mathrm{ml}$ was dispensed into six $250 \mathrm{ml}$ flasks. The $\mathrm{pH}$ of the solution was adjusted using $\mathrm{NaOH}$ and $\mathrm{HCl}$ to a range of 2 to 12 and $0.2 \mathrm{~g}$ of the adsorbent was added to the solution and allowed to stand for 48 hours. The $\mathrm{pH}$ of each solution was then determined using a potable $\mathrm{pH}$ meter and this final $\mathrm{pH}$ was recorded. A plot of the initial $\mathrm{pH}$ versus the final $\mathrm{pH}$ was prepared and the point of intersection between this line and the $45^{\circ}$ line passing through the origin gave the value of the point of zero charge. This was done for both the carbonized palm kernel chaff and the uncarbonized palm kernel chaff. 


\subsection{Preparation of Adsorbate and Batch Equilibrium Experiment}

Analytical grade stock solution of nickel nitrate was utilized and six beakers of stock nickel solutions with concentrations of $10,30,50,70,100$ and $120 \mathrm{mg} / \mathrm{L}$ were prepared using appropriate amounts of the stock solution. The $\mathrm{pH}$ was adjusted to 3.0 using $0.5 \mathrm{M} \mathrm{HCl}$ and a $\mathrm{pH}$ meter. The completely mixed batch reactor (CMBR) technique was used to investigate the adsorption of Nickel from water by putting $100 \mathrm{mg}$ of adsorbent in $100 \mathrm{ml}$ nickel solution. The batch adsorption was conducted at temperatures of $30{ }^{\circ} \mathrm{C}, 35^{\circ} \mathrm{C}$ and $40{ }^{\circ} \mathrm{C}$ for both CPKC and UPKC. The same procedure was repeated for the same concentrations of nickel solution adjusted to $\mathrm{pH} 9$ using $0.5 \mathrm{M}$ $\mathrm{NaOH}$ buffer solutions. At equilibrium, adsorbent was separated from solution by filtration with Whatman filter paper number $(0.45 \mu \mathrm{m})$. Equilibrium concentration of nickel ion was determined using an Atomic Absorption Spectroscopy Machine (Shimadzu, AA 7000). All equipment and their accessories as well as reagents (except the stock nickel nitrate solution) used were made available by the National Center for Energy Research and Development, University of Nigeria, Nsukka, Nigeria.

\subsection{Analyses of Experimental Results}

At the end of the equilibrium experiments, the quantity of $\mathrm{Ni}$ (II) adsorbed was determined. The amount of metal adsorbed per gram of adsorbent at equilibrium was calculated as follows.

$$
q_{e}=\frac{C_{o}-C_{e}}{m} V
$$

Where $q_{e}$ is the quantity of nickel removed per unit mass of adsorbent $(\mathrm{mg} / \mathrm{g}), m$ is the mass of adsorbent $(\mathrm{g}), V$ is the volume of adsorbate $(L), C_{o}$ is the initial concentration of adsorbate $(\mathrm{mg} / \mathrm{l})$ and $C_{e}$ is the equilibrium concentration of adsorbate in solution. The experimental data were fitted to six isotherms namely: Langmuir, Freundlich, Temkin and Dubinin Radushkevich (D-R), Florry- 
Huggins and Koble-Corrigan isotherms. Adsorption isotherms provide insight into the sorption mechanisms, surface properties, and affinity of adsorbent for the adsorbent ${ }^{39}$. Langmuir isotherm represents the equilibrium distribution of metal ions between the solid and liquid phases by the formation of a monolayer on the adsorbent surface containing a finite number of identical sites with uniform energies of adsorption ${ }^{40}$. The expression for the Langmuir isotherm is given as Equation 2, where $C_{e}$ is the equilibrium concentration of solute $(\mathrm{mg} / \mathrm{l}), q_{e}$ is the quantity of solute in the solid phase at equilibrium $(\mathrm{mg} / \mathrm{g}), q_{\max }$ is the maximum adsorption capacity $(\mathrm{mg} / \mathrm{g})$ and $K_{L}$ is the Langmuir constant. Both the non-linear and the linear forms of Langmuir isotherm were considered. In this study, the Langmuir types I, II, III and IV were used to fit the experimental data and are given as Equations (3) to (6).

$\underline{\text { Langmuir Isotherm }}$

$$
q_{e}=\frac{q_{\max } K_{L} C_{e}}{1+K_{L} C_{e}}
$$

Langmuir Type I

$$
\frac{C_{e}}{q_{e}}=\frac{C_{e}}{q_{\max }}+\frac{1}{q_{\max } K_{L}}
$$

Langmuir Type II - Lineweaver-Burke $\quad \frac{1}{q_{e}}=\frac{C_{e}}{q_{\max } K_{L}}+\frac{1}{q_{\max }}$

Langmuir Type II - Eadie-Hoffsie

$$
q_{e}=q_{\max }-\frac{q_{e}}{K_{L} C_{e}}
$$

$\underline{\text { Langmuir Type IV - Scatchard }}$

$$
\frac{q_{e}}{C_{e}}=q_{\max } K_{L}-K_{L} q_{e}
$$

The Freundlich adsorption isotherm describes adsorption characteristics of a heterogeneous surface. This isotherm recognizes the possibility of surface heterogeneity and intermolecular interactions between adsorbed molecules ${ }^{41}$. Freundlich and Langmuir isotherms have been the most widely used isotherms used by researchers to investigate the performance of adsorbents. The nonlinear and linear forms of Freundlich isotherm are given as Equations (7) and (8) respectively, 
where $n$ is the Freundlich intensity parameter and $K_{F}=$ Freundlich constant which is indicative of the relative adsorption capacity of the adsorbent $(\mathrm{L} / \mathrm{mg})^{1 / \mathrm{n}}$.

$q_{e}=K_{F} C_{e}^{1 / n}$

$L n q_{e}=\operatorname{Ln} K_{F}+\frac{1}{n} \operatorname{Ln} C_{e}$

The Temkin isotherm contains a factor that explicitly takes into account adsorbent - adsorbate interactions. By ignoring the extremely low and large value of concentrations, the model assumes that heat of adsorption (a function of temperature) of all molecules in the layer would decrease linearly rather than logarithmically with coverage ${ }^{42}$. The nonlinear and linear forms of Temkin isotherm are given as Equations (9) and (10), where $b$ is the Temkin constant while $A$ is the equilibrium binding constant (L/g).

$q_{e}=B \ln \left(A C_{e}\right)$

$q_{e}=B \operatorname{Ln} A+B \operatorname{Ln} C_{e}$

The Dubinin-Radushkevich (D-R) isotherm expresses the adsorption mechanism with a Gaussian energy distribution onto a heterogeneous surface. The model has often successfully fitted high solute activities and the intermediate range of concentration data well ${ }^{42}$. The D-R isotherm is generally applied to express the adsorption process occurring onto both homogenous and heterogeneous surfaces ${ }^{43}$. It is a semi empirical isotherm that assumes that sorption follows a pore filling mechanism ${ }^{44}$. The use of the $\mathrm{D}-\mathrm{R}$ isotherm is also essential for the investigation of nature of sorption using the sorption energy values $(E)$. The expression for the $\mathrm{D}-\mathrm{R}$ isotherm is given as Equation (10), where $q_{m}$ is the maximum sorption capacity $(\mathrm{mg} / \mathrm{l}), \beta$ is the activity coefficient 
related to sorption free energy and $\varepsilon$ is the Polanyi potential. The linearized form of the D-R isotherm is presented in Equation (12).

$q_{e}=q_{m} \exp \left(-\beta \varepsilon^{2}\right)$

$\varepsilon=R T \ln \left(1+\frac{1}{C_{e}}\right)$

$L n q_{e}=L n q_{m}-\beta \varepsilon^{2}$

Flory-Huggins isotherm describes the degree of surface coverage characteristics of the adsorbate on the adsorbent ${ }^{44,45}$. Theta $(\theta)$ is the degree of surface coverage, $n$ is the Flory-Huggins exponent and $K$ is the equilibrium constant $(\mathrm{L} / \mathrm{mg})$. The Flory-Hugging isotherm is presented as Equation (13) which was then log-transformed to obtain the linear form given in Equation (14).

$\frac{\theta}{C_{0}}=K(1-\theta)^{n}$

$\operatorname{Ln}\left(\frac{\theta}{C_{0}}\right)=\ln K+n \ln (1-\theta)$

The degree of surface coverage used for analysis is expressed as

$\theta=1-\frac{C_{e}}{C_{0}}$

Koble-Corrigan isotherm is a three-parameter isotherm resulting from the combination of the Langmuir and Freundlich isotherms.

$q_{e}=\frac{a C_{e}^{n}}{1+b C_{e}^{n}}$

\section{Results and Discussion}

\subsection{Chemical composition of PKC on the adsorption of $\mathrm{Ni}$}

Palm kernel chaff (PKC) is an abundant agricultural by-product which consists of $20-30 \%$ cellulose (Yan et al. 2009). CPKC and UPKC are black and dark brown in color respectively. XRF results show that the dominant elements in UPKC are S (83.86\%), $\mathrm{Ti}(10.08 \%)$ and $\mathrm{Fe}$ (3.96) while 
those in CPKC are Ca (47.16\%), K (23.82\%), S (15.69), Fe (5.10\%), Ti (4.82\%) and Mn (1.16\%). It can be seen that carbonization drastically reduced the Sulphur content of PKC. The results show that the dominant elements are Sulphur, calcium, titanium, potassium and iron. Sulphur containing compounds ionize to produce sulphites, sulphates and sulphides (with 2- anions), constituting counterions to Nickel (Ni2+). The counterions from the PKC are adsorbed on to the surface of the of Ni2+. This therefore results to the neutralization of the repulsive charges on the ionized Nickel atoms. Calcium, iron and the other elements react with the alkalinity in water to form insoluble and slightly soluble hydroxides that are precipitated out of solution. Adsorption can occur effectively through chemical bonds (covalent or ionic) between the surface hydroxyl group and the adsorbate ions (cations or anions) ${ }^{46}$.

The neutralized nickel and the precipitates are then duly adsorbed at the adsorption sites. The chemical composition of the PKC coupled with the impact of high alkalinity on chemical precipitation, further corroborates the strong affinity and favourable sorption of $\mathrm{Ni}$ (II) onto PKC at $\mathrm{pH} 9$.

\subsection{Efficiency of Sorption of Ni (II) by PKC under Various Physicochemical Conditions}

Contact time had a considerable effect on $\mathrm{Ni}$ (II) biosorption by chemically activated CPKC and UPKC. Increase in contact time resulted in a corresponding increase in biosorption efficiency up to the equilibrium time. Generally, sorption rate was slow and gradual at $\mathrm{pH} 9$ for both UPKC and CPKC, while at pH 3 the sorption efficiency was fairly rapid. The percentage removal of Ni (II) by $\mathrm{CPKC}$ at $\mathrm{pH} 9$ and $40^{\circ} \mathrm{C}$ was $100 \%, 97.2 \%, 95.9 \%, 92.8 \%, 89 \%$ and $84.9 \%$ at initial concentrations of $10 \mathrm{mg} / 1,30 \mathrm{mg} / 1,50 \mathrm{mg} / 1,70 \mathrm{mg} / 1,100 \mathrm{mg} / 1$ and $120 \mathrm{mg} / 1$. These were higher than the values of $97.9 \%, 96.5 \%, 91.8 \%, 83.5 \%, 76.9 \%$, and $71.5 \%$ respectively obtained for UPKC at the same $\mathrm{pH}$ and temperature. The corresponding percentage removal for $\mathrm{CPKC}$ at $\mathrm{pH} 3$ was 
$66.9 \%, 58.1 \%, 55.6 \%, 50.2 \%, 47.4 \%$ and $44.6 \%$, while the corresponding values for UPKC at $\mathrm{pH}$ 3 were $62.4 \%, 52.5 \%, 50.8 \%, 49.2 \%, 45.7 \%$ and $42.5 \%$. In most cases, equilibrium was attained at 90 minutes and 120 minutes in very few cases. Smooth and continuous saturation of the adsorbent surface suggests a possible monolayer coverage of metal ions. This is attributed to the fixed number of active adsorption sites in any given adsorption system, hence, each active site can only adsorb one ion in a monolayer. This makes the intake of metal ions fairly rapid at the initial stage, slowing down as available active sites decrease. Chaouch et al., ${ }^{47}$ observed that the adsorption of metal ions from an aqueous compound is very much dependent on the $\mathrm{pH}$. The $\mathrm{pH}$ governs important parameters such as the net surface charge on the adsorbent, the degree of ionization, the speciation of the adsorbent, predominant species and the dissociation of active functional sites on the biosorbent ${ }^{48}$. In this study, a high percentage adsorption of up to $100 \%$ was noted for CPKC within 60 minutes of contact at an initial concentration of $10 \mathrm{mg} / \mathrm{l}$, temperature of $40^{\circ} \mathrm{C}$ and $\mathrm{pH}$ 9. At $\mathrm{pH} \mathrm{3}$, for the same adsorbent, metal ion concentration and temperature, the percentage adsorption reduced to $66.92 \%$ which amounts to one third reduction in efficiency. The lowest percentage sorption of $24.28 \%$ was recorded for UPKC at an initial nickel concentration of $120 \mathrm{mg} / \mathrm{l}$, temperature of $30^{\circ} \mathrm{C}$ and $\mathrm{pH} 3$. The effect of $\mathrm{pH}$ on biosorption capacity in this study shows that at $\mathrm{pH} 9$, the percentage of adsorption was better than at $\mathrm{pH} 3$. The reduced sorption efficiency at $\mathrm{pH} 3$ can be attributed to the predominance of hydrogen ions in solution which restricted the adsorption of metal ions. In addition, increase in $\mathrm{pH}$ from 3 to 9 could result in the precipitation of $\mathrm{Ni}$ (II) ions due to the presence of hydroxide anions forming nickel hydroxide precipitate, thereby further reducing the concentration of $\mathrm{Ni}$ (II) ions in solution ${ }^{49}$. Arshadi et al. ${ }^{50}$ also noted that a low intake of heavy metals in an acidic medium may be as a result of particle attrition, partial protonation of the functional groups and the competition between hydrogen ions 
and metal ions for binding to the adsorption sites. The adsorption process is very dependent on $\mathrm{pH}$ and the concentration of the solution ${ }^{41}$. However, the effect of $\mathrm{pH}$ on adsorption varies according to the nature of the solute and the surface properties of the adsorbent. Hence, other researchers have obtained results which are either slightly different or even completely opposite to the results obtained in this study for different adsorbents and solutes. Raj ${ }^{51}$ observed that the adsorption of $\mathrm{Ni}$ (II) on activated carbon is efficient at $\mathrm{pH}$ less than 4.5 while Aikpokpodion et al. ${ }^{52}$ noted that the adsorption of $\mathrm{Ni}$ (II) on whole tea (Camellia Simensis) material recorded better efficiency at $\mathrm{pH}$ less than 5. Arshadi et al. ${ }^{50}$ recorded increase an adsorption efficiency of $\mathrm{Cd}$ (II), $\mathrm{Cu}$ (II) and Co (II) by barley stray ash when the $\mathrm{pH}$ of the solution was increased to 11 . Generally, sorption efficiency seems to increase with increase in $\mathrm{pH}$ for adsorbents with point of zero charge less than the $\mathrm{pH}$ of the solution, while it will decrease for adsorbents with zero-point charge greater than the $\mathrm{pH}$ of the solution.

In this study, efficiency of removal was higher at low adsorbate concentrations while the actual quantity of metal ion adsorbed increased when the adsorbate concentration increased. At $\mathrm{pH} 9$, the rate of sorption was very high in the first five minutes and then slowly attained equilibrium at 90 mins. This behavior was particularly obvious for the lowest initial concentration of $10 \mathrm{mg} / \mathrm{l}$ at all experimental conditions. For instance, for $\mathrm{CPKC}$ at $\mathrm{pH} 9$ and a temperature of $30^{\circ} \mathrm{C}$, sorption efficiency was $92.31 \%$ at 5 mins and $97.85 \%$ at 90 mins. Similarly, for same physicochemical characteristics at $\mathrm{pH} 3$, sorption efficiency was $14.1 \%$ at 5 mins and $49.18 \%$ at 90 mins. This behavior can be attributed to the high affinity between the positively charged $\mathrm{Ni}$ (II) ions and the negatively charged adsorbent surface at $\mathrm{pH}$ 9. Hence, the affinity between $\mathrm{Ni}$ (II) and PKC was highest at the beginning of the adsorption process, but decreased as the number of active sorption sites reduced. 


\subsection{Adsorption Isotherm}

Adoption isotherms were used to analyze the experimental data with a view to gaining insight into the mechanism of adoption of $\mathrm{Ni}$ (II) onto PKC at various physico-chemical conditions. Sorption isotherms are useful for the evaluation of the extent to which a sorption system can be improved as well as for the optimization of operating conditions ${ }^{53}$. Both the linear and non-linear forms of the isotherms were employed in the evaluation of the adsorption process and performances (see Table 1a and 1b). Though the linear forms of the isotherm are easier to use, the process of linearization introduces a measure of error into the final result. The error distribution of linearized isotherms varies in accordance with the linearization techniques adopted ${ }^{45}$. He et al. ${ }^{54}$ observed that the transformation of non-linear isotherms to linear forms implicitly alter the error structure and may also violate the error variance and normality assumptions of standard least squares. The effect of linearization has also been reported for Freundlich and Langmuir isotherms. Consequently, Freundlich isotherm yields better fit of experimental data at low adsorbate concentration while Langmuir isotherm yields a better fit at high adsorbate concentration ${ }^{54}$. Owing to the foregoing, both linear and nonlinear forms of the isotherms were explored in this study. The nonlinear isotherm used were Langmuir, Freundlich Koble-Corrigan, Temkin, DubininRadushkevich (D-R) and Florry-Huggins isotherms. The linearized isotherms used were Langmuir types I II III and IV, Freundlich, Temkin, D-R, Florry-Huggins and the generalized isotherm. Figures 2 is the best fit plots of experimental equilibrium data to selected isotherms. The KobleCorrigan three parameter isotherm and the D-R isotherm performed better than all the other isotherms with $\mathrm{R}^{2}$ values ranging from 0.97 to 1.0 and 0.95 to 1.0 respectively (Tables 1 and 2). They were closely followed by Freundlich isotherm with $\mathrm{R}^{2}$ value of 0.96 to 1.0 and 0.92 to 1.0 for the nonlinear and linear forms respectively. The nonlinear form of Temkin isotherm was the 
least performing of all isotherms investigated with $\mathrm{R}^{2}$ values ranging from 0.92 to 0.99 for both linear and nonlinear forms. This can be attributed to the assumption by Temkin isotherm that adsorption involves a uniform distribution of maximum binding energy ${ }^{53}$. This assumption obviously does not apply to PKC being a heterogenous substance. This might also be responsible for the relatively lower performance of Langmuir isotherm compared to the other isotherms (0.92 $\left.\leq \mathrm{R}^{2} \leq 1.0\right)$. Langmuir isotherm assumes that all binding sites are energetically equivalent. This implies that all active sites have the same probability of binding to the solute upon exposure. Again, while this may be true for homogeneous synthetic materials, it cannot apply to palm kernel chaff which is not homogenous.

The fact that the Koble-Corrigan three parameter isotherm integrates both the Langmuir and Freundlich isotherms gave it an edge over other isotherms, particularly the Langmuir and Freundlich isotherms, in fitting the experimental data. The Koble-Corrigan isotherm will reduce to either the Langmuir isotherm or the Freundlich isotherm, depending on experimental conditions. The Koble-Corrigan parameter $n$ is equivalent to the inverse of the Freundlich intensity parameter $(1 / n)$, whereas the isotherm constant $b$ is equivalent to Langmuir constant $K_{L}$. The values of the Koble-Corrigan parameter $n$ ranged from 0.45 to 0.73 for $\mathrm{CPKC}$ at $\mathrm{pH} 9,0.27$ to 0.73 for UPKC at $\mathrm{pH} 9,0.71$ to 1.10 for $\mathrm{CPKC}$ at $\mathrm{pH} 3$ and 0.71 to 1.01 for UPKC at $\mathrm{pH} 3$. The corresponding values for Freundlich parameter $(1 / n)$ are 0.35 to $0.42,0.34$ to $0.51,0.64$ to 0.68 and 0.61 to 0.74 . The lowest percentage differences of $3.5 \%$ and $4.3 \%$ between the two isotherm parameters were calculated for CPKC at $30^{\circ} \mathrm{C}, \mathrm{pH} 9$ and UPKC at $35^{\circ} \mathrm{C}, \mathrm{pH}$ 3. On the other hand, the values of Langmuir constant $K_{L}$ ranged from 0.197 to 0.369 for CPKC at pH 9, 0.058 to 0.316 for UPKC at $\mathrm{pH} 9,0.011$ to 0.017 for $\mathrm{CPKC}$ at $\mathrm{pH} 3$ and 0.008 to 0.015 for UPKC at $\mathrm{pH} 3$. These values are of the same order of magnitude with the Koble-Corrigan constant $(b)$ with corresponding values of 
0.106 to $0.29,-0.203$ to $0.151,0.003$ to 0.015 and -0.004 to 0.014 . The two parameters have identical values of 0.012 for UPKC at $\mathrm{pH} 3$ and a temperature of $40{ }^{\circ} \mathrm{C}$. However, despite the striking agreement for the case mentioned above, there are wide disparities in a number of cases such as for CPKC at $40{ }^{\circ} \mathrm{C}$ and $\mathrm{pH} 9, \mathrm{UPKC}$ at $35^{\circ} \mathrm{C}$ and $\mathrm{pH} 9, \mathrm{CPKC}$ at $30^{\circ} \mathrm{C}$ and $\mathrm{pH} 3, \mathrm{UPKC}$ at $35{ }^{\circ} \mathrm{C}$ and $\mathrm{pH} 3$ where the percentage differences are $215.4 \%, 147.8 \%, 266.7 \%$ and $300 \%$ respectively. The foregoing suggests that the adsorption of $\mathrm{Ni}$ (II) onto palm kernel chaff tends more towards a Freundlich process than a Langmuir process.

Nonetheless, it is expedient to consider in details the performance of the Langmuir isotherm because its derivation was based on a more mechanistic process than, for instance, the Freundlich isotherm and it enables the comparison of different adsorbents by using their maximum adsorption capacities $\left(q_{\max }\right)^{53}$. The nonlinear and linear forms of Langmuir (type II) performed better in acidic medium of $\mathrm{pH} 3$ with $\mathrm{R}^{2}$ values ranging from 0.97 to 1.0 than in basic medium of $\mathrm{pH} 9\left(0.92 \leq \mathrm{R}^{2}\right.$ $\leq 0.99$ ). But the linear Langmuir isotherm (type I) performed relatively better in basic medium $\left(0.94 \leq \mathrm{R}^{2} \leq 0.99\right)$ than in acidic medium $\left(0.92 \leq \mathrm{R}^{2} \leq 0.96\right)$. The effect of linearization was immediately obvious with respect to Langmuir isotherm. The nonlinear and type I linear isotherms were of the same order of accuracy in the basic medium, but the performance of the type I linear isotherm deteriorated noticeably at $\mathrm{pH} 3\left(0.92 \leq \mathrm{R}^{2} \leq 0.96\right)$. Surprisingly, the type II linearized Langmuir isotherm performed much better $\left(0.96 \leq \mathrm{R}^{2} \leq 1.0\right)$ than the nonlinear isotherm as well as the other three types. Langmuir isotherm (type IV) was the least performing of all isotherms (linear and nonlinear) investigated with $\mathrm{R}^{2}$ value ranging from 0.82 to 0.90 for all conditions except for UPKC at $\mathrm{pH} 9$ and $35^{\circ} \mathrm{C}$ where a very low $\mathrm{R}^{2}$ value of 0.25 was recorded. The Florry-Huggins isotherms performed relatively well $\left(\mathrm{R}^{2}=0.99\right)$ at all conditions accept for $\mathrm{CPKC}$ at $35^{\circ} \mathrm{C}$ and $\mathrm{pH}$ $9\left(\mathrm{R}^{2}=0.52\right)$ as a result of undesirable asymptotic behaviour observed at low adsorbate 
concentration of $10 \mathrm{mg} / \mathrm{L}$. Overall, Temkin and D-R isotherms were hardly affected by the process of linearization. All isotherms that have a tendency towards undesirable asymptotic behavior seem to performed a little better when linearized. Hence, linearization becomes a better and necessary option under such circumstances.

"Table 1a: Sorption Isotherm Parameters for Non-linear Fitting"

"Table 1b: Sorption Isotherm Parameters for Linear Fitting"

"Figure 2a: Plots of fits of equilibrium data to isotherms at $\mathrm{pH} 3$ "

"Figure 2b: Plots of fits of equilibrium data to isotherms at $\mathrm{pH} 9 "$

\subsection{Adsorbent performance}

The sorption capacity of PKC at different conditions was determined based on Langmuir isotherm type II which yielded the best fit for the experimental data compared to other Langmuir-type isotherms. Careful examination of the isotherm parameters suggests that the other forms of Langmuir isotherm exaggerated the maximum sorption capacity PKC. This can be misleading and result in wrong sizing of adoption systems. The range of maximum sorption capacity obtained using the various forms are 34.62 to $110.2,48.8$ to $108.1,36.0$ to $120.6,41.5$ to 99.1 and 47.8 to $104.1 \mathrm{mg} / \mathrm{g}$ for the nonlinear and linear types I, II, III and IV respectively. Apart from the experiment carried out using $\mathrm{CPKC}$ at $35^{\circ} \mathrm{C}$ and $\mathrm{PH} 9$, the maximum sorption capacity obtained using the type II isotherm yielded the least value at all conditions. The Langmuir type II isotherm yielded the most reliable values of maximum sorption capacity because it had the highest $R^{2}$ value and the least error. Based on the foregoing the, optimum condition for the adsorption of $\mathrm{Ni}$ (II) onto PKC corresponds to $\mathrm{pH} 9$ and a temperature of $35^{\circ} \mathrm{C}$. Generally, $\mathrm{CPKC}$ had better adsorption 
capacity with maximum sorption capacity $\left(q_{\max }\right)$ ranging between 65.4 and $120.6 \mathrm{mg} / \mathrm{g}$ than UPKC with $q_{\max }$ ranging from 36.0 to $65.9 \mathrm{mg} / \mathrm{g}$. Besides, the sorption capacity of CPKC was significantly enhanced at a basic $\mathrm{pH}$ compared to acidic $\mathrm{pH}$. For instance, the maximum sorption capacity of CPKC at PH 9.0 was $120.6 \mathrm{mg} / \mathrm{g}$ which is just about double that of UCPK at $\mathrm{pH} 3.0$. This value of maximum sorption capacity was higher than the values of $102.2 \mathrm{mg} / \mathrm{g}, 16.6 \mathrm{mg} / \mathrm{g}$ and 29.41 $\mathrm{mg} / \mathrm{g}$ obtained for the sorption of $\mathrm{Ni}$ (II) by protonated rice bran, orange peel and powder of Mosambi fruit peelings respectively ${ }^{49}$; but agrees very closely with the $120.5 \mathrm{mg} / \mathrm{l}$ recorded by Shah et al. ${ }^{55}$ for the sorption of Ni (II) by tea leaf treated with formaldehyde. The performance of the adsorbents was also investigated using the Freundlich intensity parameter $(n)$ obtained for the various conditions investigated. As shown in Tables 1 and 2, the values of $n$ ranged from 1.98 to 2.97 for $\mathrm{pH} 9$ and 1.35 to 1.63 for $\mathrm{pH} 3$. The values of $n>1.0$ indicate that the sorption of $\mathrm{Ni}$ (II) onto PKC is favourable and that the percentage adsorbed decrease with increasing concentration. All values of $n$ obtained in this study were greater than 1.0 were found to be highly correlated with $\mathrm{pH}(\mathrm{R}=0.9)$. Higher values of $n$ were recorded for both CPKC and UPKC at $\mathrm{pH} 9$ than at $\mathrm{pH} 3$. Hence, the sorption of $\mathrm{Ni}$ (II) onto PKC is more favourable at high $\mathrm{pH}(9)$ than at lower $\mathrm{pH}$ (3). This can be attributed to the values of the zero-point charge $\left(\mathrm{pH}_{\mathrm{zpc}}\right)$ of the material which were found to be 4.6 and 4.1 for UPKC and CPKC respectively. $\mathrm{pH}_{\mathrm{zpc}}$ is the $\mathrm{pH}$ of the adsorbent at which the total surface charge is zero and the values of $\mathrm{pH}_{\mathrm{zpc}}$ obtained suggest that acid groups are more dominant than basic groups ${ }^{56}$. It can be seen from the $\mathrm{pH}_{\mathrm{zpc}}$ values that carbonization further reduced the point of zero charge, thus further strengthening the force of attraction between the adsorbent and $\mathrm{Ni}$ (II) ions in solution. This further suggests affinity with a positively charged ion such as $\mathrm{Ni}$ (II). When the $\mathrm{pH}$ of the medium is greater than the $\mathrm{pH}_{\mathrm{zpc}}$, the $\mathrm{PKC}$ will assume net negative surface charge and hence will have increased affinity for the positively charged Ni (II) 
ion. On the other hand, when the $\mathrm{pH}$ of the medium is less than the $\mathrm{pH}_{\mathrm{zpc}}$, the surface of the adsorbent will assume a net positive charge, resulting in electrostatic repulsion between PKC and $\mathrm{Ni}$ (II) and a subsequent reduction in the sorption on Ni (II) onto PKC. This accounts for the reduced performance of $\mathrm{PKC}$ at $\mathrm{pH}$ 3. It has been established that the sorption of cations will be more favourable at a $\mathrm{pH}$ above the $\mathrm{pH}_{\mathrm{zpc}}$ of the adsorbent, while the adsorption of anions will be more favourable at a $\mathrm{pH}$ less than the $\mathrm{pH}_{\mathrm{zpc}}$ and vice versa ${ }^{57}$. Another reason for increased performance of the adsorbent at $\mathrm{pH} 9$ is that increase in $\mathrm{pH}$ enhances deprotonation of the functional groups on the surface of the palm kernel chaff, thereby creating more negatively charged sites and increasing the performance of the adsorbent ${ }^{58}$. Ghasemi et al. ${ }^{59}$ also reported that as $\mathrm{pH}$ of solution increased, the sorption of $\mathrm{Ni}$ (II) by grape shell ash became more favourable as a result of increased negative surface charge of the adsorbent leading to greater electrostatic attraction between solute and adsorbate. To further explore the favorability of Ni (II) sorption onto PKC, the Langmuir separation factor $R_{L}$ was determined for all cases studied. The Langmuir separation coefficient is expressed as

$R_{L}=\frac{1}{1+K_{l} C_{O}}$

The value of $R_{L}$ gives an indication of the relative affinity between adsorbate (Ni) and adsorbent PKC) and is usually classified as follows.

$R_{L}>1 \rightarrow$ unfavourable

$R_{L}=1 \rightarrow$ linear

$0 \leq R_{L} \leq 1 \rightarrow$ favourable

$R_{L}=0 \rightarrow$ irreversible 
The value of $R_{L}$ ranged from 0.022 to $0.337,0.026$ to $0.633,0.342$ to 0.901 and 0.41 to 0.926 for CPKC at pH 9, UPKC at pH 9, CPKC at pH 3 and UPKC at pH 3 responsively. This shows that the sorption of $\mathrm{Ni}$ (II) onto PKC is very favorable and that there is strong affinity between PKC and Ni (II). The lowest values of $R_{L}$ were obtained for $\mathrm{CPKC}$ at $\mathrm{pH} 9$ and $40^{\circ} \mathrm{C}\left(0.022 \leq R_{L} \leq\right.$ 0.213), while the highest values were obtained for UPKC at $\mathrm{pH} 3$ and $35^{\circ} \mathrm{C}\left(0.51 \leq R_{L} \leq 0.926\right)$. The lower the value of $R_{L}$, the more favourable the sorption process. Figure 3 shows that the sorption of $\mathrm{Ni}$ (II) onto PKC is more favorable at higher concentrations of the adsorbate and this can be attributed to the increased contact between adsorbent and adsorbate as well as increased concentration potential between the solid and liquid phase. The value of $R_{L}$ tends to 1 at low $\mathrm{pH}$ and low concentration indicating a tendency towards unfavorable condition.

"Figure 3: Plots of Langmuir separation factor for different temperatures and $\mathrm{pH} "$

The sorption mechanism was studied using the activity coefficient $(\beta)$ of the D-R isotherm. Beta $(\beta)$ is related to the sorption energy $(E)$ by the expression.

$E=\frac{1}{\sqrt{-2 \beta}}$

The sorption energy $(E)$ represent the energy required for moving one mole of the solute from infinity to the surface of the adsorbent ${ }^{53}$. Values of $E<8 \mathrm{~kJ} / \mathrm{mol}$ indicate physical sorption; $E>$ $16 \mathrm{~kJ} / \mathrm{mol}$ indicates chemical sorption; while intermediate values of $8 \leq E \leq 16 \mathrm{~kJ} / \mathrm{mol}$ signify ion exchange. The values of $E$ obtained ranged between 14.27 and $8.21 \mathrm{~kJ} / \mathrm{mol}$. These values suggest that the mode of sorption is ion exchange. Shen et al. ${ }^{58}$ identified cation exchange as the predominant mode of sorption of $\mathrm{Ni}$ (II) by biochars made from wheat straw pellets and rice husk. The values of $E$ ranged from 8.21 to $8.76 \mathrm{~kJ} / \mathrm{mol}$ at $\mathrm{pH} 3$ and from 9.96 to 14.27 at $\mathrm{pH} 9$. The value 
of $E$ increased with temperature at $\mathrm{pH} 9$ but decreased slightly with temperature at $\mathrm{pH} 3$. The results reveal that the mode of sorption of Ni (II) onto PKC could be physisorption, ion exchange or chemisorption depending on physicochemical conditions under which sorption is taking place. Tran et al. ${ }^{60}$ noted that adsorption can be by physisorption, chemisorption or a mixture of both. Shen et al. ${ }^{58}$ further noted that the sorption of Ni (II) onto biochars was accomplished by other mechanisms besides cation exchange. Figure 4 suggests that the mode of sorption is temperaturedependent and that at higher temperatures than those studied, the sorption process may transit to chemisorption. On the other hand, the process tends towards physisorption at lower pH. Kumar ${ }^{61}$ observed that the forces involved in physical sorption are weak and that the energy requirement is small, hence equilibrium is easily attained and reversible.

"Figure 4: Sorption energy of CPKC and UPKC for different $\mathrm{pH} "$

The surface coverage of PKC by Ni (II) ions was calculated as follows.

$C=\frac{q_{e}}{q_{\max }} \times 100$

Better coverage was obtained at higher temperature and $\mathrm{pH}$. CPKC recorded higher surface coverage than UPKC (Figure 5). The maximum coverage obtained for each of the experimental cases were $99.3 \%$ for $\mathrm{UPKC}$ at $\mathrm{pH} 9$ and $40^{\circ} \mathrm{C}, 92 \%$ for $\mathrm{CPKC}$ at $\mathrm{pH} 9$ and $35^{\circ} \mathrm{C}, 55.4 \%$ for $\mathrm{CPKC}$ at $\mathrm{pH} 3$ and $35^{\circ} \mathrm{C}$; and $50 \%$ for UPKC at $\mathrm{pH} 3$ and $40^{\circ} \mathrm{C}$. Higher values of surface coverage were obtained at higher concentrations of $\mathrm{Ni}$ (II) and higher $\mathrm{pH}$. The surface coverage is a measure of the degree of active site utilization by the solute. Hence, higher surface coverage indicates greater utilization of available sites. 
"Figure 5: Plots of surface coverage of adsorbents for different temperatures and $\mathrm{pH}$ "

\subsection{Thermodynamics of Ni (II) Adsorption by PKC}

Thermodynamics provide a practical tool for the estimation of the chemical state of adsorbent and the solution in chemical industry application ${ }^{62}$. In order to ascertain the feasibility of the process, Gibbs free energy was computed for all experimental conditions. Gibbs free energy $\Delta G^{o}$ was computed as follows.

$\Delta G^{\circ}=-R T \operatorname{Ln} K_{o}$

$\Delta G^{\circ}=\Delta H-T \Delta S$

Hence

$\operatorname{LnK}_{0}=\frac{\Delta S}{R}-\frac{\Delta H}{R}\left(\frac{1}{T}\right)$

Where $\Delta \mathrm{G}^{\mathrm{o}}$ is Gibbs free energy $(\mathrm{kJ} / \mathrm{mol}), R$ is the universal gas constant $(\mathrm{kJ} / \mathrm{mol} / \mathrm{K}), T$ is temperature $(\mathrm{K}), \Delta \mathrm{H}$ is enthalpy change and $K_{o}$ is standard equilibrium constant. The values of $K_{o}$ used in this work were obtained using Langmuir constant $K_{L}$. The major problem with the use of $K_{L}$ obtained from Langmuir isotherm is that while $K_{o}$ is dimensionless, $K_{L}$ has a unit of $\mathrm{L} / \mathrm{mg}$. This is a major issue that is often overlooked in adsorption studies. In order to satisfy the requirement that $K_{o}$ be dimensionless, the values of $K_{L}$ were modified as suggested by Milonjic ${ }^{63}$ and Zhou and Zhou ${ }^{64}$. While Milonjic ${ }^{63}$ suggested that $K_{L}$ can be made dimensionless by multiplying with $10^{6}$, Zhou and Zhou ${ }^{64}$ suggested multiplying by 5500. Applying the above recommendations, Table 2 was generated. $\Delta \mathrm{S}$ and $\Delta \mathrm{H}$ were obtained from the intercept and slope of the plot of $\operatorname{Ln} K_{o}$ versus $1 / T$ which yielded a straight line graph. The values of $\Delta \mathrm{G}^{\mathrm{o}}$ obtained as recommended by Zhou and Zhou ${ }^{64}$ were slightly higher than those obtained by adopting the suggestion of Milonjic ${ }^{63}$. However, the two methods lead to similar deductions with respect to thermodynamic parameters 
and sorption mechanism. The values of $\Delta G^{o}$ obtained were as follows $-33.69 \leq \Delta G^{0} \leq-36.43$ $\mathrm{kJ} / \mathrm{mol},-30.6 \leq \Delta \mathrm{G}^{\mathrm{o}} \leq-36.03,-26.33 \leq \Delta \mathrm{G}^{\mathrm{o}} \leq-28.3 \mathrm{~kJ} / \mathrm{mol}$ and $-26.03 \leq \Delta \mathrm{G}^{\mathrm{o}} \leq-27.4 \mathrm{~kJ} / \mathrm{mol} . \Delta \mathrm{G}^{\mathrm{o}}$ is a measure of the spontaneity of the sorption process and the negative values suggest that the sorption of Ni (II) onto PKC is feasible and spontaneous. Table 2 shows that the adsorption process is more feasible at $\mathrm{pH} 9$ than at $\mathrm{pH} 3$.

"Figure 6: Plots of Gibbs free energy of adsorbents for different $\mathrm{pH} "$

Figure 6 clearly shows that carbonization makes sorption of Ni (II) onto PKC more energetically feasible by enhancing the porosity of the adsorbent. The values of $\Delta \mathrm{H}$ obtained are $-49.7,-133.5$, -33.8 and $17.4 \mathrm{~kJ} / \mathrm{mol}$ for $\mathrm{CPKC}$ at $\mathrm{pH} 9, \mathrm{UPKC}$ at $\mathrm{pH} \mathrm{9,} \mathrm{CPKC} \mathrm{at} \mathrm{pH} 3$ and $\mathrm{UPKC}$ at $\mathrm{pH} 3$ respectively. These values indicate that the process is exothermic for $\mathrm{CPKC}$ regardless of $\mathrm{pH}$ but exothermic for UPKC at $\mathrm{pH} 9$ and endothermic at $\mathrm{pH} 3$. Shah et al. ${ }^{55}$ also reported that the sorption of Ni (II) by formaldehyde-treated tea leaf was both exothermic and spontaneous. However, Alandis et al. ${ }^{65}$ found that the sorption of $\mathrm{Ni}$ (II) by natural bentonite was endothermic. In exothermic reaction, less energy is required for bond breaking than that required for bond formation. The positive values of $\Delta \mathrm{S}$ suggest that some structural changes occurred on the adsorbent, and confirms that affinity exists between the adsorbent and adsorbate ${ }^{54}$. The values of $\Delta \mathrm{S}^{\mathrm{o}}$ also suggest that the process is entropy-driven. Saha and Chowdhury ${ }^{21}$ observed that the heat evolved during physical sorption is of the same order of magnitude as the heat of condensation $(2.1-20.9 \mathrm{~kJ} / \mathrm{mol})$ while heat of chemisorption generally falls within the values of $80-200 \mathrm{~kJ} / \mathrm{mol}$ 62. The values of enthalpy change $\left(17.44 \leq \Delta \mathrm{H}^{\mathrm{o}} \leq 49.65 \mathrm{~kJ} / \mathrm{mol}\right)$ obtained in this study lies between these two ranges aforementioned for all cases investigated except for UPKC at $\mathrm{pH} 9$ with $\Delta \mathrm{H}^{\mathrm{o}}=$ 
$133.5 \mathrm{~kJ} / \mathrm{mol}$. This suggests that the sorption of $\mathrm{Ni}$ (II) onto PKC can be accomplished either by chemisorption or ion exchange depending on experimental conditions. The values of $\Delta \mathrm{H}^{\circ}$ for UPKC at $\mathrm{pH} 9$ suggests a chemisorption but the corresponding values of sorption energy $(8.21 \leq$ $\mathrm{E} \leq 14.27)$ suggest otherwise. In order to further understand the adsorption mechanism, the isosteric heat of adsorption $\left(\Delta \mathrm{H}_{\mathrm{x}}\right)$ was computed. According to Saha and Chowdhury ${ }^{21}$, the isosteric heat of sorption is the most relevant thermodynamic property for describing heat effects during adsorption process. It is a very important parameter for characterization and optimization of adsorption process which also gives an indication about the surface heterogeneity of the adsorbent ${ }^{21}$. The expression for the isosteric heat of sorption is given below.

$\operatorname{LnC} C_{e}=-\left[\frac{\Delta H_{x}}{R}\right] \frac{1}{T}+K$

$K$ is a constant while $C_{e}$ is the equilibrium concentration of $\mathrm{Ni}$ (II) in solution and the other parameters retain their usual meanings as earlier defined. The isosteric heat of sorption $\Delta \mathrm{H}_{\mathrm{x}}$ was obtained from the slope of plots of $L n C_{e}$ versus $1 / T$. The values of $\Delta \mathrm{H}_{\mathrm{x}}$ obtained were $-62.0 \leq \Delta \mathrm{H}_{\mathrm{x}}$ $\leq-22.68,-133.09 \leq \Delta \mathrm{H}_{\mathrm{x}} \leq-21.34,-33.87 \leq \Delta \mathrm{H}_{\mathrm{x}} \leq-17.92$ and $-24 \leq \Delta \mathrm{H}_{\mathrm{x}} \leq-19.21 \mathrm{~kJ} / \mathrm{mol}$ for $\mathrm{CPKC}$ at $\mathrm{pH} 9, \mathrm{UPKC}$ at $\mathrm{pH} 9, \mathrm{CPKC}$ at $\mathrm{pH} 3$ and UPKC at $\mathrm{pH} 3$. Twenty-two (22) of the 24 values of $\Delta \mathrm{H}_{\mathrm{x}}$ were less than $80 \mathrm{~kJ} / \mathrm{mol}$ while 23 of the 24 values were greater than $20.9 \mathrm{~kJ} / \mathrm{mol}$ suggesting an intermediate state between physisorption and chemisorption. Saha and Chowdhury ${ }^{21}$ noted that for chemical sorption $\Delta \mathrm{H}_{\mathrm{x}}$ should range between 80 and $400 \mathrm{~kJ} / \mathrm{mol}$. Contrary to the findings of this study, Temel ${ }^{66}$ reported that the sorption of $\mathrm{Ni}$ (II) by gyttja was purely by physical sorption. Physisorption usually involves weak Van der Waal forces, ion exchange involves coulombic forces while chemisorption involves the formation of covalent bond between the solute and the surface of the adsorbent. The variation of $\Delta \mathrm{H}_{\mathrm{x}}$ with surface loading (Figure 7) indicate that the adsorbents 
have energetically heterogenous surfaces. Higher values of $\Delta \mathrm{H}_{\mathrm{x}}$ were obtained at low adsorbate concentration suggesting the existence of highly active sites on the surfaces of the adsorbents ${ }^{21}$.

"Figure 7: Plots of $L n C_{e}$ versus $1 / T$ for determination of isosteric heat of sorption".

"Table 2: Thermodynamic parameters computed according to Zhou and Zhou ${ }^{64}$ and Milonjic ${ }^{63 "}$

\section{Conclusion}

PKC makes an excellent biosorbent at $\mathrm{pH} 9.0$ and $40^{\circ} \mathrm{C}$ especially when carbonized before chemical activation. Hence, CPKC generally had higher adsorption capacity than UPKC. Complete removal (100\%) of $\mathrm{Ni}$ (II) from solution was recorded for $\mathrm{CPKC}$ at $\mathrm{pH} 9$ in 60 minutes. One gram $(1 \mathrm{~g})$ of the biosorbent can remove as much as 120.6mg of nickel from aqueous solution by mostly ion exchange for a complete monolayer coverage. This was higher than the maximum monolayer adsorption capacity recorded by other researchers for rice bran, orange peel and powder of Mosambi fruit peelings. The sorption process was more favourable in basic medium ( $\mathrm{pH}$ 9) than in acidic medium ( $\mathrm{pH}$ 3) because the point of zero charge which was 4.6 for UPKC and 4.1 for CPKC. The sorption of Ni (II) by palm kernel chaff was adequately described by the KobleCorrigan and D-R isotherms with very high coefficients of correlation. The Freundlich isotherm was also found to fit the experimental data. The linear type II Langmuir isotherm performed much better than both the nonlinear type as well as the other linear types. The values of Freundlich intensity parameters $(n)$ and Langmuir separation coefficients $\left(R_{L}\right)$ revealed that the sorption on $\mathrm{Ni}$ (II) onto PKC is more favourable at higher solute concentrations. The values of sorption energy (E) and isosteric heat of sorption $\left(\Delta \mathrm{H}_{\mathrm{x}}\right)$ confirmed that the sorption process is an ion exchange process under the physicochemical conditions used in the study. The sorption of Ni (II) onto PKC is exothermic, spontaneous, entropy-driven and highly feasible. Higher values of isosteric heat of 
sorption $\left(\Delta \mathrm{H}_{\mathrm{x}}\right)$ at low adsorbate concentrations suggest the availability of highly active sorption sites on the surface of the adsorbents. 


\section{REFERENCES}

1. Nuithitikul, K., Phromrak, R. \& Saengngoen, W. Utilization of chemically treated cashewnut shell as potential adsorbent for removal of $\mathrm{Pb}(\mathrm{II})$ ions from aqueous solution. Sci. Rep. 10, 1-14 (2020).

2. Çelebi, H., Gök, G. \& Gök, O. Adsorption capability of brewed tea waste in waters containing toxic lead(II), cadmium (II), nickel (II), and zinc(II) heavy metal ions. Sci. Rep. 10, 1-12 (2020).

3. ATSDR. Toxicology Profile for Nickel. Toxicol. Profile Nickel 1-397 (2005).

4. USAF. Nickel, In: The Installation Restoration Program Toxicology Guide. 1, (1989).

5. El-Naggar, N. E. A. \& Rabei, N. H. Bioprocessing optimization for efficient simultaneous removal of methylene blue and nickel by Gracilaria seaweed biomass. Sci. Rep. 10, 1-21 (2020).

6. Jacob, J. J., Varalakshmi, R., Gargi, S., Jayasri, M. A. \& Suthindhiran, K. Removal of Cr (III) and $\mathrm{Ni}$ (II) from tannery effluent using calcium carbonate coated bacterial magnetosomes. npj Clean Water 1, (2018).

7. Bui, N. T. et al. A nature-inspired hydrogen-bonded supramolecular complex for selective copper ion removal from water. Nat. Commun. 11, 1-12 (2020).

8. Do, Q. C., Choi, S., Kim, H. \& Kang, S. Adsorption of lead and nickel on to expanded graphite decorated with manganese oxide nanoparticles. Appl. Sci. 9, (2019).

9. Rathor, G., Chopra, N. \& Adhikari, T. Nickel as a Pollutant and its Management. Int. Res. J. Environ. Sci. 3, 94-98 (2014).

10. Goyer, R. et al. Issue paper on the human health effects of metals. U.S. EPA 1-48 (2003).

11. Coogan, T. P., Latta, D. M., Snow, E. T. \& Costa, M. Toxicity and Carcinogenicity of Nickel Compounds. in CRC Critical Reviews in Toxicology 19, 341-384 (1989).

12. Smialowicz, R. J., Rogers, R. R., Riddle, M. M. \& Stott, G. A. Immunologic effects of nickel: I. Suppression of cellular and humoral immunity. Environ. Res. 33, 413-427 (1984).

13. Smialowicz, R. J. et al. Immunologic effects of nickel. Environ. Res. 36, 56-66 (1985).

14. Smialowicz, R. J., Rogers, R. R., Rowe, D. G., Riddle, M. M. \& Luebke, R. W. The effects of nickel on immune function in the rat. Toxicology 44, 271-281 (1987).

15. Bocca, B. \& Forte, G. The epidemiology of contact allergy to metals in the general population: Prevalence and new evidences. Open Chem Biomed Methods J 2, 26-349 (2009).

16. Järup, L. Hazards of heavy metal contamination. Br. Med. Bull. 68, 167-82 (2003).

17. Durosaro, O. \& El-Azhary, R. A. A 10-year retrospective study on palladium sensitivity. Dermat. contact, atopic, Occup. drug 20, 208-13 (2009). 
18. Thyssen, J. P., Linneberg, A., Menné, T. \& Johansen, J. D. The epidemiology of contact allergy in the general population--prevalence and main findings. Contact Dermatitis 57, 287-299 (2007).

19. Mohan, D. \& Singh, K. P. Single- and multi-component adsorption of cadmium and zinc using activated carbon derived from bagasse - An agricultural waste. Water Res. 36, 23042318 (2002).

20. Kobya, M., Demirbas, E., Senturk, E. \& Ince, M. Adsorption of heavy metal ions from aqueous solutions by activated carbon prepared from apricot stone. Bioresour. Technol. 96, 1518-1521 (2005).

21. Saha, P. \& Chowdhury, S. Insight Into Adsorption Thermodynamics. Thermodynamics (2011). doi:10.5772/13474

22. Chojnacka, K. Biosorption and bioaccumulation - the prospects for practical applications. Environ. Int. 36, 299-307 (2010).

23. Kurniawan, T. A., Chan, G. Y. S., Lo, W. hung \& Babel, S. Comparisons of low-cost adsorbents for treating wastewaters laden with heavy metals. Sci. Total Environ. 366, 409426 (2006).

24. Mudgal, V., Madaan, N., Mudgal, A., Singh, R. B. \& Mishra, S. Effect of Toxic Metals on Human Health. Open Nutraceuticals J. 3, 94-99 (2010).

25. Kim, J. W., Sohn, M. H., Kim, D. S., Sohn, S. M. \& Kwon, Y. S. Production of granular activated carbon from waste walnut shell and its adsorption characteristics for $\mathrm{Cu} 2+$ ion. $J$. Hazard. Mater. 85, 301-315 (2001).

26. Demirbaş, Ö., Karadağ, A., Alkan, M. \& Doğan, M. Removal of copper ions from aqueous solutions by hazelnut shell. J. Hazard. Mater. 153, 677-684 (2008).

27. Emenike, P. C., Omole, D. O., Ngene, B. U. \& Tenebe, I. T. Potentiality of agricultural adsorbent for the sequestering of metal ions from wastewater. Glob. J. Environ. Sci. Manag. 2, 411-442 (2016).

28. Emenike, P. C., Omole, D. O., Ngene, B. U., Tenebe, I. T. \& Maxwell, O. Experimental investigation of copper removal from aqueous solution using Musa Paradisiaca as a novel adsorbent. WIT Trans. Ecol. Environ. 216, 173-179 (2017).

29. Reimann, C. \& de Caritat, P. Chemical Elements in the Environment. Chemical Elements in the Environment (Springer Berlin Heidelberg, 1998). doi:10.1007/978-3-642-72016-1

30. Singh, C. K. et al. Studies on the removal of $\mathrm{Pb}(\mathrm{II})$ from wastewater by activated carbon developed from Tamarind wood activated with sulphuric acid. J. Hazard. Mater. 153, 221228 (2008).

31. Demiral, H., Demiral, I., Tümsek, F. \& Karabacakoğlu, B. Adsorption of chromium(VI) from aqueous solution by activated carbon derived from olive bagasse and applicability of different adsorption models. Chem. Eng. J. 144, 188-196 (2008).

32. Kadirvelu, K. et al. Utilization of various agricultural wastes for activated carbon 
preparation and application for the removal of dyes and metal ions from aqueous solutions. Bioresour. Technol. 87, 129-132 (2003).

33. Hussein, H., Ibrahim, S. F., Kandeel, K. \& Moawad, H. Biosorption of heavy metals from waste water using Pseudomonas sp. Electron. J. Biotechnol. 7, 45-53 (2004).

34. Carvalho, L. P. F. et al. Evaluation of palm kernel meal and corn distillers grains in corn silage-based diets for lactating dairy cows. J. Dairy Sci. 89, 2705-2715 (2006).

35. Silas, S., Sailaja, D. \& Rao, G. H. Use Of Palm Kernel Cake As Low Cost Biosorbent For The Removal Of Cadmium From Aqueous Solution. IOSR J. Environ. Sci. Toxicol. Food Technol. 11, 38-50 (2017).

36. Evbuomwan, B. O., Agbede, A. M. \& Atuka, M. M. A Comparative Study of the PhysicoChemical Properties of Activated Carbon from Oil Palm Waste (Kernel Shell and Fibre). Int. J. Sci. Eng. Investig. 2, 75-79 (2013).

37. Ho, Y. S. \& Ofomaja, A. E. Kinetic studies of copper ion adsorption on palm kernel fibre. J. Hazard. Mater. 137, 1796-1802 (2006).

38. Singh, J., Mishra, N. S., Uma, Banerjee, S. \& Sharma, Y. C. Comparative studies of physical characteristics of raw and modified sawdust for their use as adsorbents for removal of acid dye. BioResources 6, 2732-2743 (2011).

39. Khan, T., Ali, I., Singh, V. \& Sharma, S. Utilization of fly ash as low-cost adsorbent for the removal of methylene blue, malachite green and rhodamine B dyes from textile wastewater. J. Environ. Prot. Sci. 3, 11-22 (2009).

40. Lipovský, M., Sirotiak, M. \& Soldán, M. Removal Of Copper From Aqueous Solutions By Using Natural And Fe-Modified Clinoptilolite. Res. Pap. Fac. Mater. Sci. Technol. Slovak Univ. Technol. 23, 33-40 (2015).

41. Nnaji, C., Ebeagwu, C. \& Ugwu, E. Physicochemical Conditions for Adsorption of Lead from Water by Rice Husk Ash. Bioresource 12, 799-818 (2017).

42. Dada, A. O., Olalekan, A. P., Olatunya, A. M. \& Dada, O. Langmuir, Freundlich, Temkin and Dubinin-Radushkevich Isotherms Studies of Equilibrium Sorption of Zn2+ Unto Phosphoric Acid Modified Rice Husk. IOSR J. Appl. Chem. 3, 38-45 (2012).

43. Chen, X. Modeling of experimental adsorption isotherm data. Information 6, 14-22 (2015).

44. Ayawei, N., Ebelegi, A. N. \& Wankasi, D. Modelling and Interpretation of Adsorption Isotherms. J. Chem. 2017, (2017).

45. K.Y. Foo, B. H. H. Insights into the modeling of adsorption isotherm systems. Chem. Eng. J. 156, 2-10 (2010).

46. Qasim, S. R., Motley, E. M. \& Zhu, G. Water works engineering: Planning, design and operation. (New Delhi, India: Phi Learning, 2000).

47. Chaouch, N., Ouahrani, M. R. \& Laouini, S. E. Adsorption of lead (II) from aqueous solutions onto activated carbon prepared from Algerian dates stones of phoenix dactylifera L (Ghars variety) by H3PO4 activation. Orient. J. Chem. 30, 1317-1322 (2014). 
48. Couto, O. M. et al. Effect of solution $\mathrm{pH}$ and influence of water hardness on caffeine adsorption onto activated carbons. Can. J. Chem. Eng. 93, 68-77 (2015).

49. Krishna, R. H. \& Swamy, A. Studies on the Removal of Ni (II) from Aqueous Solutions Using Powder of Mosambi Fruit Peelings as a Low Cost Sorbent. Chem. Sci. J. 2, 1-13 (2011).

50. Arshadi, M., Amiri, M. J. \& Mousavi, S. Kinetic, equilibrium and thermodynamic investigations of $\mathrm{Ni}(\mathrm{II}), \mathrm{Cd}(\mathrm{II}), \mathrm{Cu}(\mathrm{II})$ and $\mathrm{Co}(\mathrm{II})$ adsorption on barley straw ash. Water Resources and Industry 6, (Elsevier, 2014).

51. Raj, S. . Adsorption behaviour of nickel on activated carbonNo Title. Indian J. Environ. Prot. 24, 530-533 (2005).

52. Aikpokpodion, P. E., Ipinmoroti, R. R. \& Omotoso, S. M. Biosorption of Nickel (II) from Aqueous Solution Using Waste Tea (Camella cinencis) Materials. Am. J. Toxicol. Sci. 2, 72-82 (2010).

53. Hubbe, M. A., Hasan, S. H. \& Ducoste, J. J. Cellulosic substrates for removal of pollutants from aqueous systems: A review. 1. Metals. BioResources 6, 1-201 (2011).

54. He, J., Hong, S., Zhang, L., Gan, F. \& Ho, Y. S. Equilibrium and thermodynamic parameters of adsorption of Methylene blue onto rectorite. Fresenius Environ. Bull. 19, 2651-2656 (2010).

55. Shah, J., Jan, M. R., Ul Haq, A. \& Zeeshan, M. Equilibrium, kinetic and thermodynamic studies for sorption of $\mathrm{Ni}$ (II) from aqueous solution using formaldehyde treated waste tea leaves. J. Saudi Chem. Soc. 19, 301-310 (2015).

56. Tran, H. N., Chao, H.-P. \& You, S.-J. Activated carbons from golden shower upon different chemical activation methods: Synthesis and characterizations. Adsorpt. Sci. Technol. 026361741668483 (2017). doi:10.1177/0263617416684837

57. Haq, A. ul et al. Evaluation of sorption mechanism of $\mathrm{Pb}$ (II) and $\mathrm{Ni}$ (II) onto pea (Pisum sativum) peels. J. Oleo Sci. 66, 735-743 (2017).

58. Shen, Z., Zhang, Y., McMillan, O., Jin, F. \& Al-Tabbaa, A. Characteristics and mechanisms of nickel adsorption on biochars produced from wheat straw pellets and rice husk. Environ. Sci. Pollut. Res. 24, 12809-12819 (2017).

59. Ghasemi, N., Ghasemi, M. \& Khosravi-Fard, Y. The Sorption of Ni(II) by Grape Shell Ash from Aqueous Solution: Kinetic and Thermodynamic Studies. Indian J. Mater. Sci. 2013, 1-6 (2013).

60. Tran, H. N., You, S. J. \& Chao, H. P. Thermodynamic parameters of cadmium adsorption onto orange peel calculated from various methods: A comparison study. J. Environ. Chem. Eng. 4, 2671-2682 (2016).

61. Kumar, U. Thermodynamics of the Adsorption of Cd(II) from Aqueous Solution on NCRH Cylinder. Int. J. Environ. Sci. Dev. 2, 334-336 (2011).

62. Zelentsov, V. \& Datsko, T. Thermodynamics of Fluorine Adsorption Onto Modified Trepel. 
Termotehnica 25-30 (2013).

63. Milonjić, S. K. A consideration of the correct calculation of thermodynamic parameters of adsorption. J. Serbian Chem. Soc. 72, 1363-1367 (2007).

64. Zhou, X. \& Zhou, X. the Unit Problem in the Thermodynamic Calculation of Adsorption Using the Langmuir Equation. Chem. Eng. Commun. 201, 1459-1467 (2014).

65. Alandis, N. M., Aldayel, O. A., Mekhemer, W. K., Hefne, J. A. \& Jokhab, H. A. Thermodynamic and kinetic studies for the adsorption of $\mathrm{Fe}(\mathrm{III})$ and $\mathrm{Ni}(\mathrm{II})$ ions from aqueous solution using natural bentonite. J. Dispers. Sci. Technol. 31, 1526-1534 (2010).

66. Temel, F. A. Kinetics and thermodynamics of the Ni(II) ions sorption from industrial wastewater by gyttja. Int. J. Exergy 23, 279-297 (2017). 


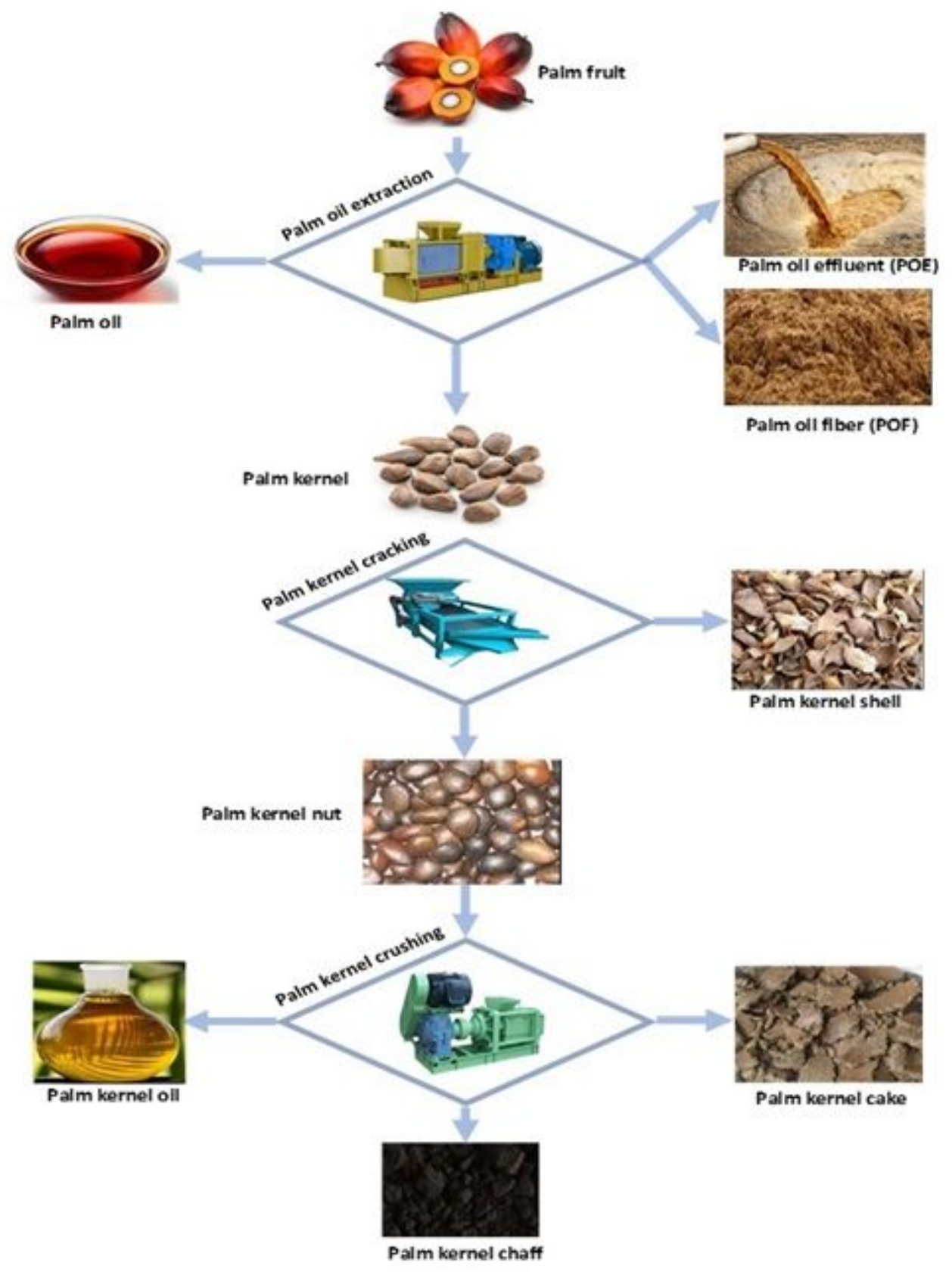

Figure 1

Process flow for primary components of palm fruit 

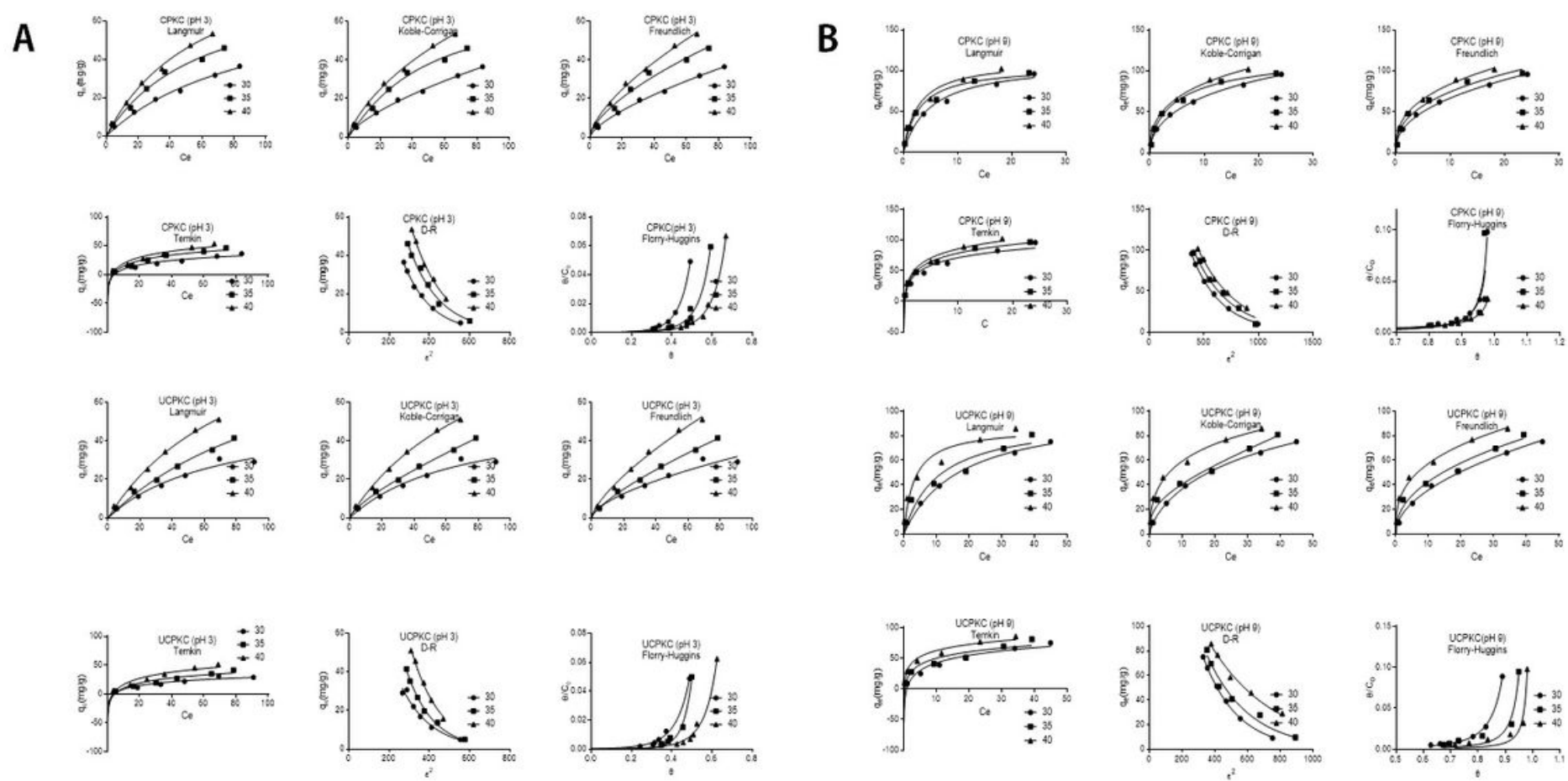

Figure 2

a: Plots of fits of equilibrium data to isotherms at $\mathrm{pH} 3$ and different temperatures. b: Plots of fits of equilibrium data to isotherms at $\mathrm{pH} 9$ and different temperatures.
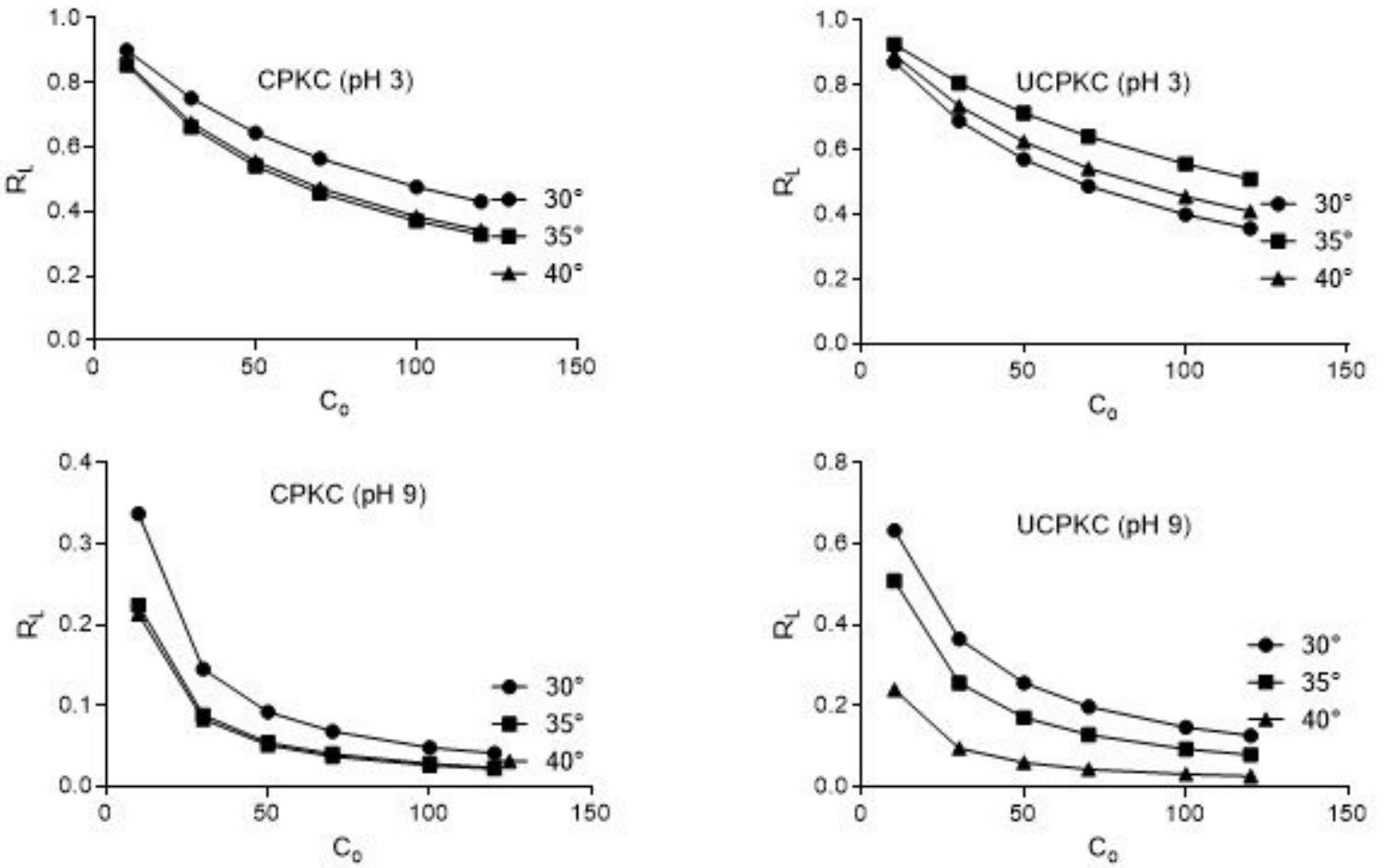

Figure 3 
Plots of Langmuir separation factor for different temperatures and $\mathrm{pH}$

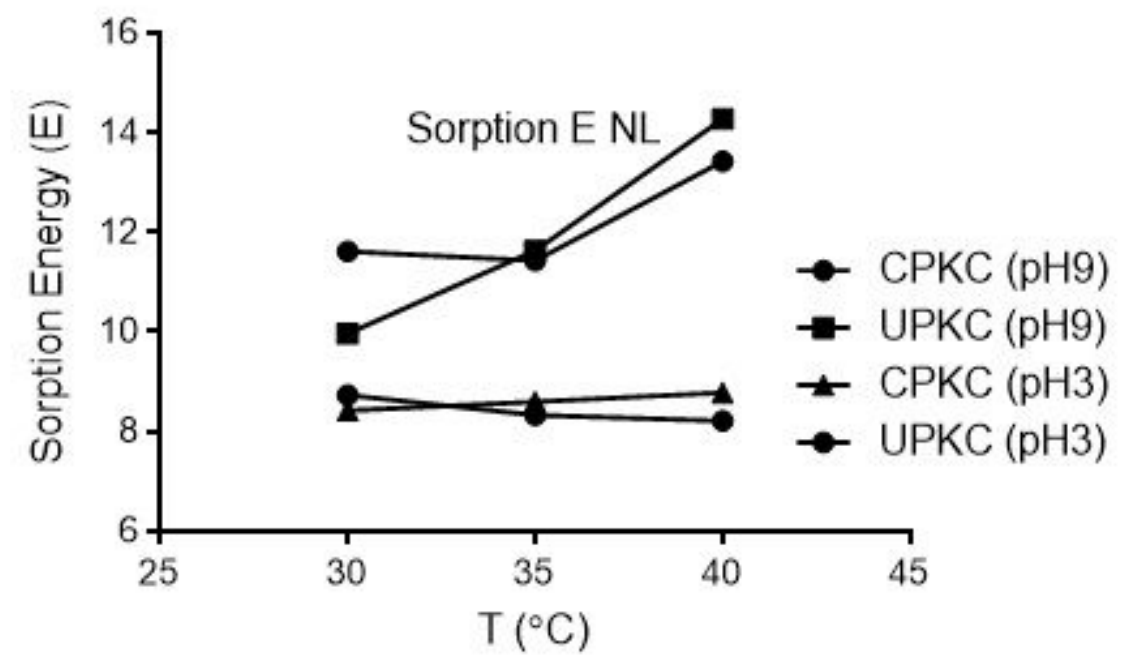

Figure 4

Sorption energy of CPKC and UPKC for different $\mathrm{pH}$
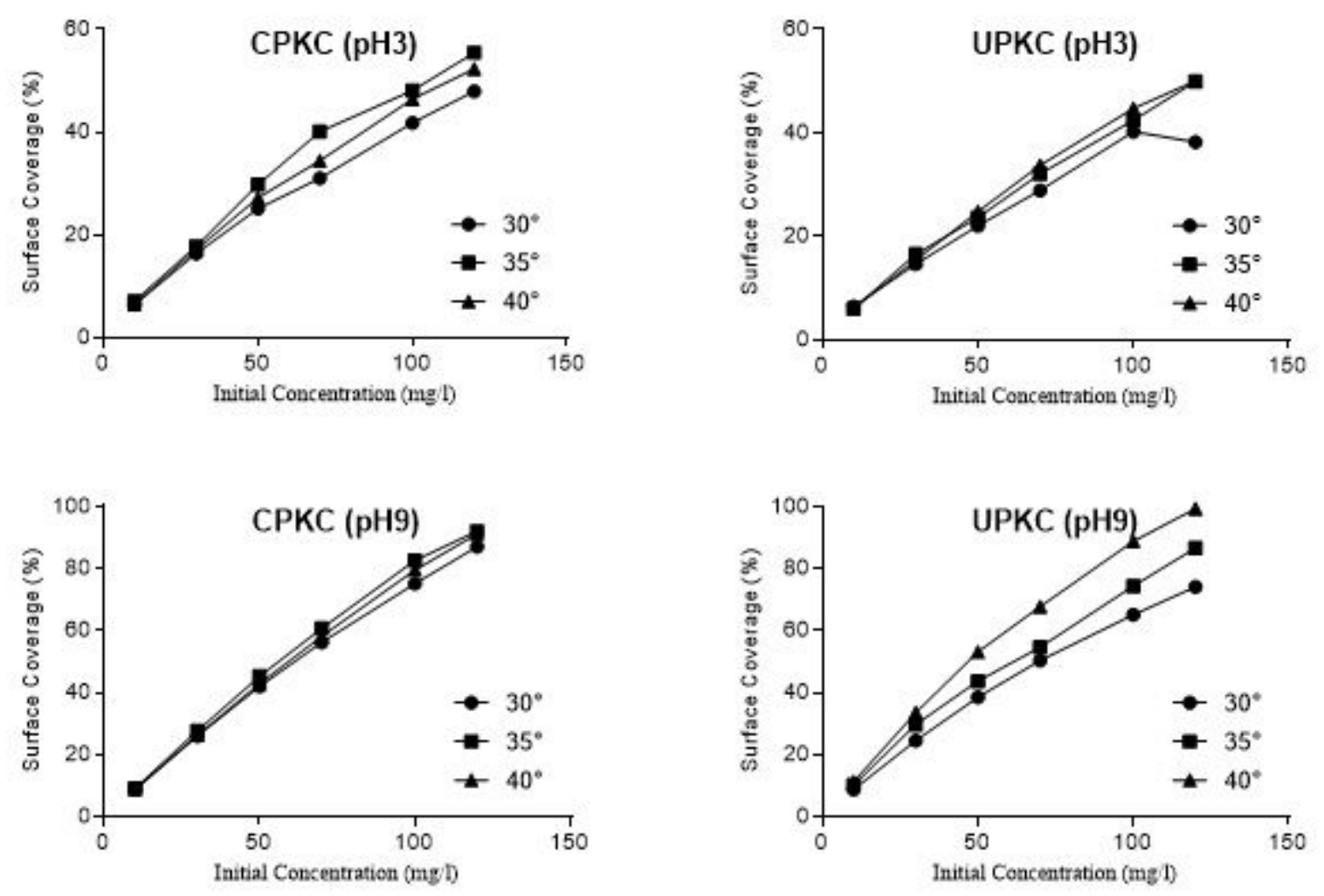

Figure 5

Plots of surface coverage of adsorbents for different temperatures and $\mathrm{pH}$ 


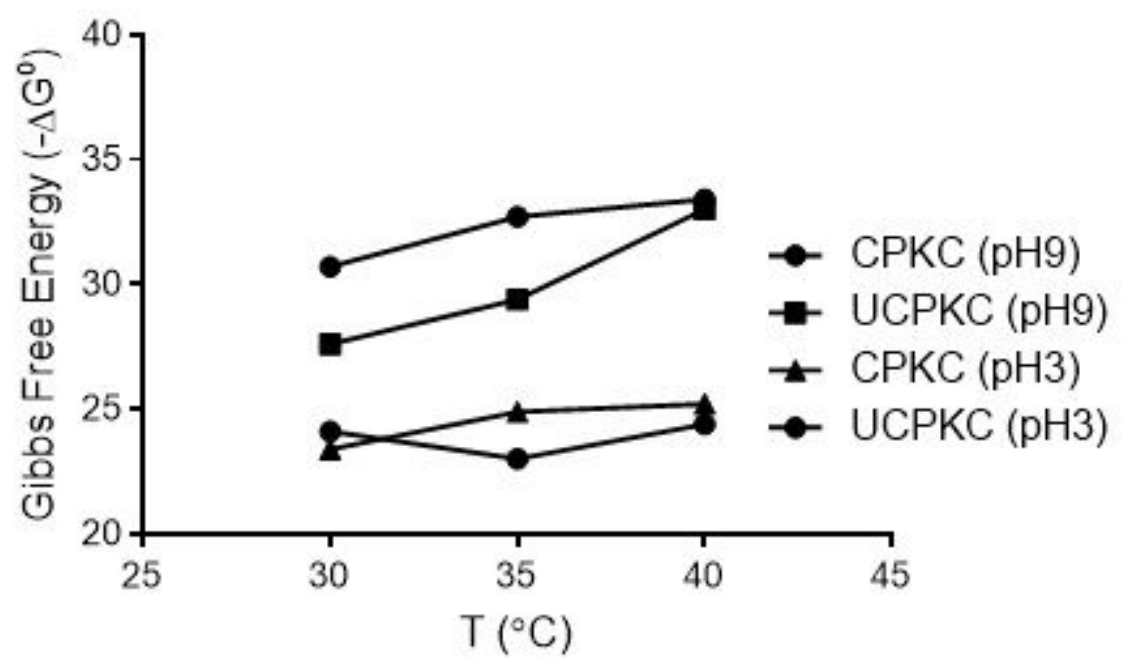

Figure 6

Plots of Gibbs free energy of adsorbents for different $\mathrm{pH}$
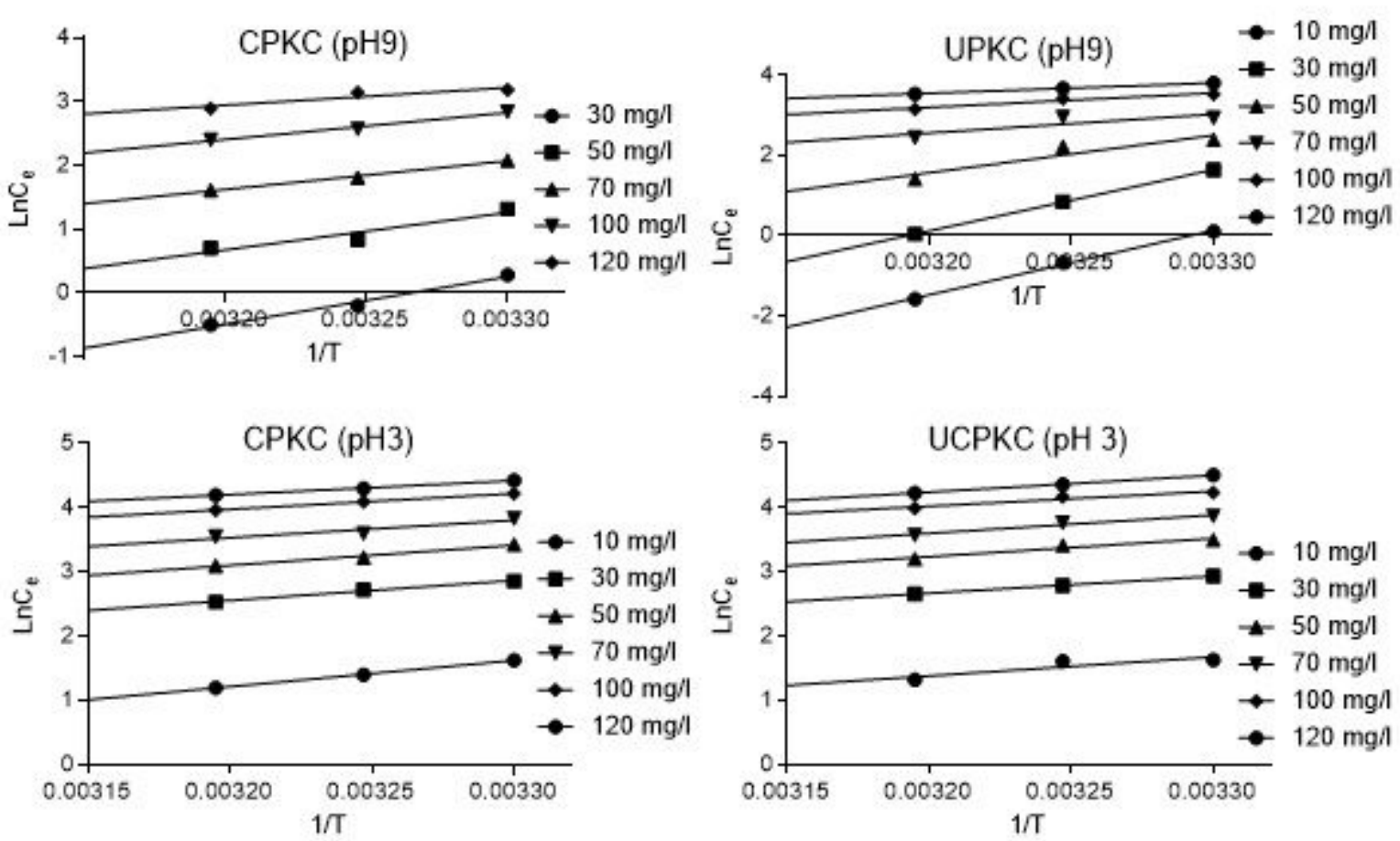

Figure 7

Plots of LnCe versus $1 / T$ for determination of isosteric heat of sorption. 